\title{
Ibuprofen enhances TRAIL-induced apoptosis through DR5 upregulation
}

\author{
MOMOKO TODO $^{1,2^{*}}$, MANO HORINAKA $^{1 *}$, MITSUHIRO TOMOSUGI $^{1 *}$, \\ RYOICHI TANAKA ${ }^{1}$, HARUNA IKAWA ${ }^{1}$, YOSHIHIRO SOWA ${ }^{1}$, HIDEKI ISHIKAWA ${ }^{1}$, \\ HITOSHI FUJIWARA ${ }^{2}$, EIGO OTSUJI ${ }^{2}$ and TOSHIYUKI SAKAI ${ }^{1}$ \\ Departments of ${ }^{1}$ Molecular-Targeting Cancer Prevention, ${ }^{2}$ Digestive Surgery, Graduate School of Medical Science, \\ Kyoto Prefectural University of Medicine, Kawaramachi-Hirokoji, Kamigyo-ku, Kyoto 602-8566, Japan
}

Received June 25, 2013; Accepted July 29, 2013

DOI: $10.3892 /$ or.2013.2713

\begin{abstract}
Numerous human chemoprevention studies have demonstrated that non-steroidal anti-inflammatory drugs (NSAIDs) possess chemopreventive effects against a variety of malignant tumors. However, there have been many clinical studies on aspirin, but not ibuprofen, even though ibuprofen is one of the most clinically and safely used NSAIDs showing potent anti-inflammatory effects. Moreover, we reported that many chemopreventive agents enhance the apoptosis-inducing effects of tumor necrosis factor-related apoptosis-inducing ligand (TRAIL), which is known to be crucial for cancer prevention. We, therefore, investigated whether ibuprofen enhances the cytocidal effect of TRAIL and found that ibuprofen markedly stimulated the apoptosis-inducing efficacy of TRAIL against human colon cancer HCT116 cells. As detected by western blot analysis and real-time RT-PCR, ibuprofen upregulated the expression of death receptor 5 (DR5), a TRAIL receptor. TRAIL-induced apoptosis enhanced by ibuprofen was effectively decreased by a caspase inhibitor and dominant-negative DR5. Noteworthy, co-treatment of ibuprofen with TRAIL did not enhance apoptosis in normal peripheral blood mononuclear cells (PBMCs). These results demonstrated that ibuprofen and
\end{abstract}

Correspondence to: Professor Toshiyuki Sakai, Department of Molecular-Targeting Cancer Prevention, Graduate School of Medical Science, Kyoto Prefectural University of Medicine, KawaramachiHirokoji, Kamigyo-ku, Kyoto 602-8566, Japan

E-mail: tsakai@koto.kpu-m.ac.jp

\section{${ }^{*}$ Contributed equally}

Abbreviations: NSAIDs, non-steroidal anti-inflammatory drugs; TRAIL, tumor necrosis factor-related apoptosis-inducing ligand; PARP, poly(ADP-ribose) polymerase; DR5, death receptor 5; BAX, Bcl2-associated X protein; XIAP, X-linked inhibitor of apoptosis; cIAP1, cellular inhibitor of apoptosis 1; PBMCs, peripheral blood mononuclear cells

Key words: ibuprofen, DR5, TRAIL, apoptosis
TRAIL synergistically induced apoptosis in human colon cancer HCT116 cells but not in normal PBMCs, raising the possibility that ibuprofen may be promising as a safe chemopreventive agent against colon cancer.

\section{Introduction}

Colorectal cancer is the second most common cancer in developed countries (1); therefore, chemoprevention for colorectal cancer is indispensable. Clinical and preclinical studies provide strong evidence that non-steroidal anti-inflammatory drugs (NSAIDs) can prevent numerous types of malignant tumors (2,3), particularly colorectal cancer (4-7). Also in Japan, double-blind randomized clinical trials have been registered to elucidate the preventive effects of low-dose aspirin on colorectal cancer and adenoma growth $(8,9)$. Among these studies, many reports on aspirin have been published; however, a greater risk of bleeding complications remains with aspirin (10), and its chemopreventive potential might be limited. Thus, we focused on ibuprofen, one of the most commonly used NSAIDs as a worldwide over-the-counter (OTC) drug. The anti-inflammatory effect of ibuprofen was found to exceed aspirin (11) and the side effects are fewer than other NSAIDs.

In general, NSAIDs inhibit cyclooxygenase (COX)-1 and COX-2, which are key enzymes of prostaglandin biosynthesis. Several independent molecular investigations have shown that COX-2 is overexpressed in $67-83 \%$ of human colon tumors $(12,13)$. The chemopreventive effects of NSAIDs have been reported due to their ability to inhibit the production of proliferative and inflammatory prostaglandins (PGs), particularly PGE2. Thus, specific COX-2 inhibitors, developed as a means to reduce the gastrointestinal toxicity associated with inhibiting COX-1, are expected to be used for chemoprevention against colorectal cancer (14). However, it has been elucidated that treatment with specific COX-2 inhibitors is associated with an increased incidence of adverse cardiovascular events, even after short-term exposure $(15,16)$. Nevertheless, there is a similar reduction in the risk of human colon cancer by selective and nonselective COX-2 inhibitors $(17,18)$. In contrast, ibuprofen inhibits both COX-1 and COX-2 equally, and causes G1-phase arrest by decreasing cyclin D1 expression and 
apoptosis by suppressing Bcl-2 and survivin (19-21). However, there have been no clinical studies on whether ibuprofen has a chemopreventive effect.

Moreover, we reported that many chemopreventive agents enhance the apoptosis-inducing effects of tumor necrosis factor-related apoptosis-inducing ligand (TRAIL) (22-25). TRAIL is a member of the TNF family and induces apoptosis in many types of malignant tumor cells in vitro and in vivo, but has little or no toxicity in normal cells $(26,27)$. Death receptor 5 (DR5; also called TRAIL-R2) and death receptor 4 (DR4) are receptors for TRAIL. A soluble recombinant human TRAIL is undergoing phase I/II clinical trials for the treatment of solid malignant tumors (28-30). Furthermore, endogenous TRAIL plays an important role in the inhibition of carcinogenesis, since TRAIL deficiency accelerates the growth of malignancies in mice (31). Activation of the TRAIL signaling pathway is considered an attractive option for cancer treatment and prevention.

In the present study, we found that ibuprofen markedly stimulated the apoptosis-inducing efficacy of TRAIL against human colon cancer HCT116 cells, but not against normal human peripheral blood mononuclear cells, and ibuprofen may be a safer chemopreventive candidate than aspirin.

\section{Materials and methods}

Reagents. Ibuprofen was purchased from Nacalai Tesque (Kyoto, Japan) and dissolved in dimethyl sulfoxide (DMSO). Soluble recombinant human TRAIL/Apo2L was obtained from PeproTech (London, UK). The human recombinant DR5 (TRAIL-R2)/Fc chimera and caspase inhibitor, zVAD-fmk, were purchased from R\&D Systems (Minneapolis, MN, USA).

Cell culture. Human colon cancer HCT116 cells were purchased from the American Type Culture Collection (Manassas, VA, USA). Cells were maintained in Dulbecco's modified Eagle's medium (DMEM) supplemented with 10\% fetal bovine serum (FBS), $4 \mathrm{mM}$ glutamine, $100 \mathrm{U} / \mathrm{ml}$ penicillin and $100 \mu \mathrm{g} / \mathrm{ml}$ streptomycin. Normal peripheral blood mononuclear cells (PBMCs) were isolated using Lymphoprep (Axis-Shield, Oslo, Norway) and maintained in RPMI-1640 medium with $10 \%$ FBS and $2 \mathrm{mM}$ glutamine. PBMCs were acquired from healthy volunteers after obtaining informed consent. This study was approved by the Kyoto Prefectural University of Medicine Research Ethics Committee (permission no. C-919). All cells were incubated at $37^{\circ} \mathrm{C}$ in a humidified atmosphere of $5 \% \mathrm{CO}_{2}$.

Detection of apoptosis. DNA fragmentation was quantified based on the percentage of hypodiploid DNA (sub-G1). After being washed with phosphate-buffered saline (PBS), the collected cells were suspended in a $0.1 \%$ Triton-X 100/PBS solution. They were then treated with RNase A (Sigma, St. Louis, MO, USA) and the nuclei were stained with propidium iodide (Sigma). The DNA content was measured using FACSCalibur (Becton Dickinson, Franklin Lakes, NJ, USA). For each experiment, 10,000 events were analyzed. Cell Quest software (Becton Dickinson) was used to analyze the data.
Western blot analysis. The cell lysate was prepared as previously described (32). The cell lysate was resolved on a 5, 7.5, 10 or $12.5 \%$ SDS-polyacrylamide gel for electrophoresis, and blotted onto polyvinylidene difluoride (PVDF) membranes (Millipore, Bedford, MA, USA). Rabbit polyclonal anti-DR4, anti-DR5 (Prosci Inc., Poway, CA, USA), anti-survivin (R\&D Systems), anti-Bcl-2 (Abcam, Cambridge, UK), anti-Bax, anti-c-IAP1, anti-caspase-3, anti-Bid, anti-PARP (Santa Cruz Biotechnology, Santa Cruz, CA, USA), and mouse monoclonal anti-XIAP (R\&D Systems), anti-caspase-8, anti-caspase-9 (MBL, Nagoya, Japan), and anti- $\beta$-actin (Sigma) antibodies were used as the primary antibodies. The blots were incubated with the appropriate HRP-conjugated secondary antibody (GE Healthcare, Piscataway, NJ, USA), and signals were detected with Chemilumi-One (Nacalai Tesque).

Determination of TRAIL receptor expression. Cells were harvested by short trypsinization, washed once with ice-cold PBS containing $1 \%$ bovine serum albumin (BSA), and resuspended in $100 \mu \mathrm{l}$ PBS with $1 \%$ BSA. Then, PE-labeled mouse anti-human DR4 or DR5 mAb (eBioscience, San Diego, CA, USA) was added. To assess nonspecific staining, PE-labeled control IgG isotypes (eBioscience) were applied. After a 30 -min incubation on ice, cells were washed and $2 \times 10^{4}$ cells were analyzed by FACSCalibur.

RNA analysis. Total cellular RNA was extracted using Sepasol-RNA I (Nacalai Tesque), according to the manufacturer's instructions. For quantitative real-time RT-PCR, total RNA $(2 \mu \mathrm{g})$ was reverse-transcribed to cDNA in a $20 \mu \mathrm{l}$ reaction volume, using a High Capacity cDNA reverse transcription kit (Applied Biosystems, Foster City, CA, USA) according to the manufacturer's instructions. Quantitative real-time RT-PCR was carried out using an RT-PCR system GeneAmp7300 (Applied Biosystems). Real-time quantitative reverse transcription-PCR primer-probe sets for DR5 and GAPDH mRNA were purchased from Applied Biosystems. The expression level of DR5 mRNA was normalized against the level of GAPDH mRNA in the same sample.

Statistical analysis. Data are the means \pm SD of three determinations. Data were analyzed using the Student's t-test, and differences were considered significant at $\mathrm{P}<0.05$.

\section{Results}

Combined treatment with ibuprofen and TRAIL induces synergistic apoptosis in HCT116 cells. It has been reported that NSAIDs have antiproliferative effects on human colon cancer. In the present study, we investigated the effect of an NSAID, ibuprofen, and/or exogenous recombinant human TRAIL on apoptosis in human colon cancer HCT116 cells. We quantified apoptotic cells by measuring the sub-G1 population. Whereas treatment with ibuprofen or TRAIL only weakly induced apoptosis (Fig. 1A and B), the combination of ibuprofen and TRAIL synergistically induced apoptosis (Fig. 1C).

Ibuprofen induces DR5 expression in HCT116 cells. To investigate the underlying mechanisms by which ibuprofen enhances 

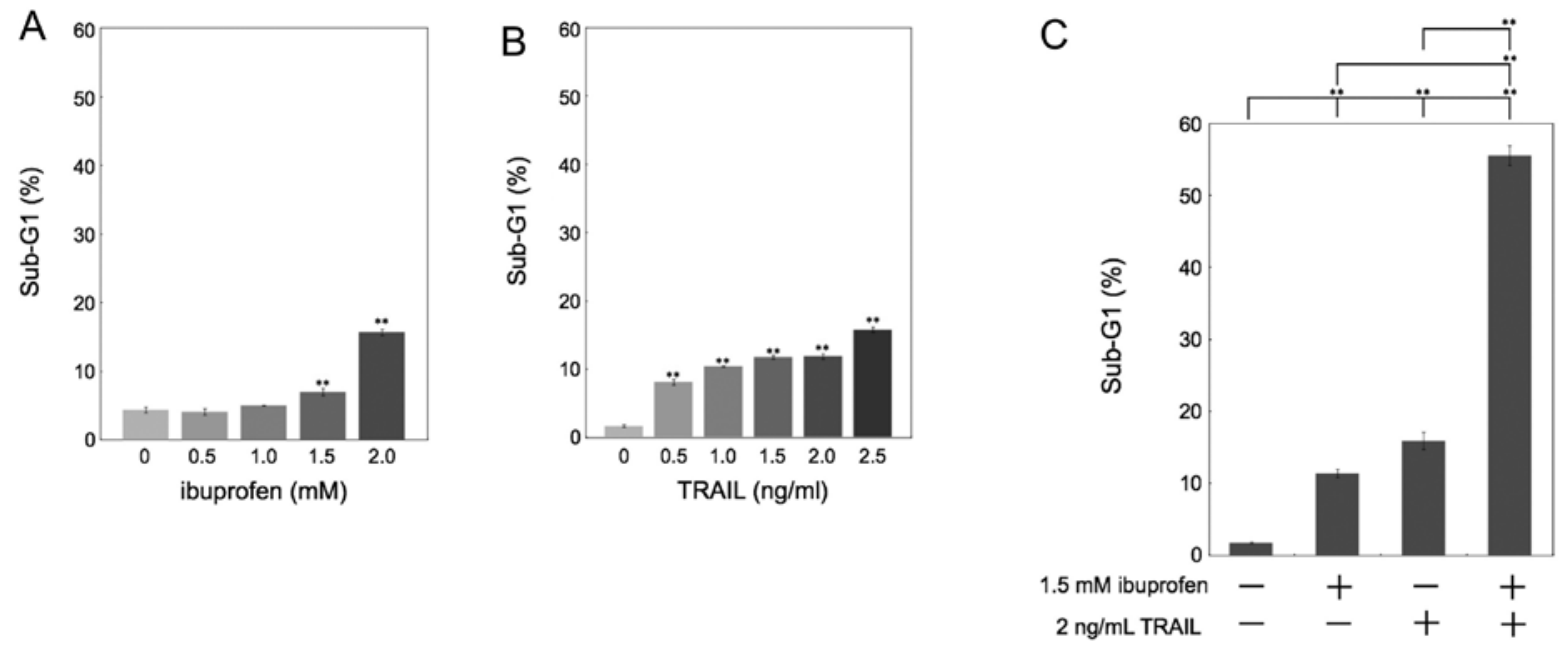

Figure 1. Ibuprofen sensitizes HCT116 cells to TRAIL-induced apoptosis. (A) HCT116 cells were treated with the indicated concentrations of ibuprofen for $24 \mathrm{~h}$. (B) HCT116 cells were treated with the indicated concentrations of TRAIL for $24 \mathrm{~h}$. (C) Combined effects of $1.5 \mathrm{mM}$ ibuprofen and/or $2 \mathrm{ng} / \mathrm{ml}$ TRAIL for $24 \mathrm{~h}$. Sub-G1 populations were analyzed by flow cytometry. Data are the means \pm SD of 3 determinations. ${ }^{* *} \mathrm{P}<0.01$.
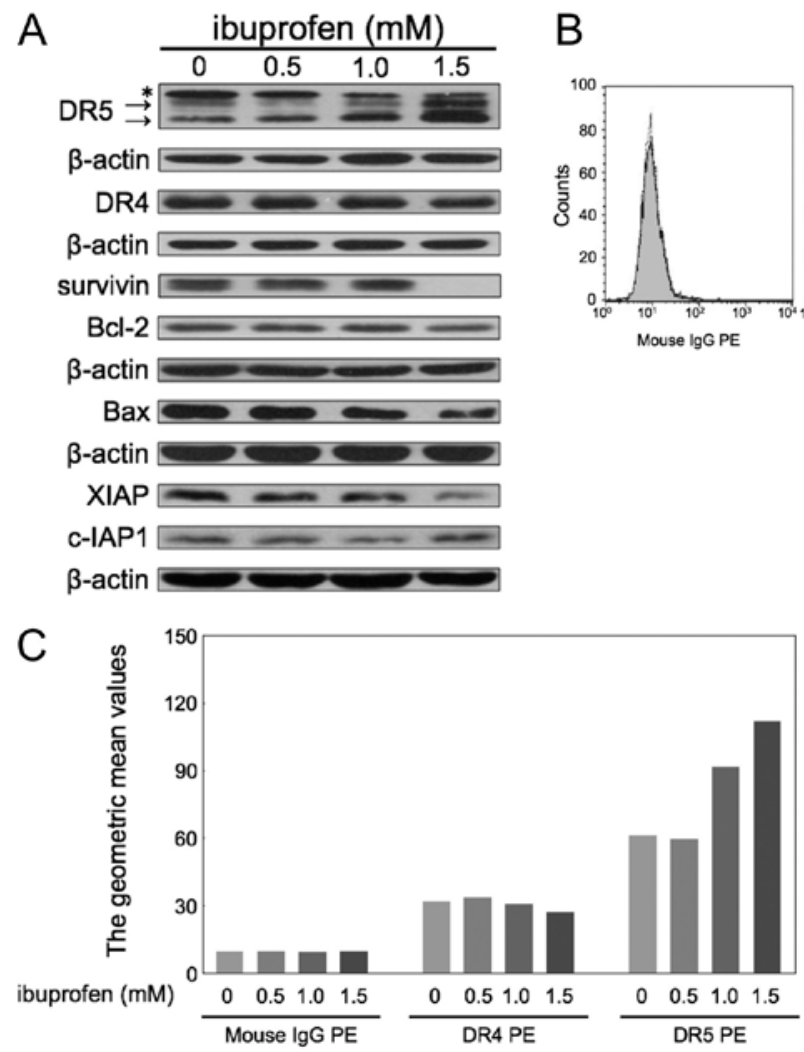

B

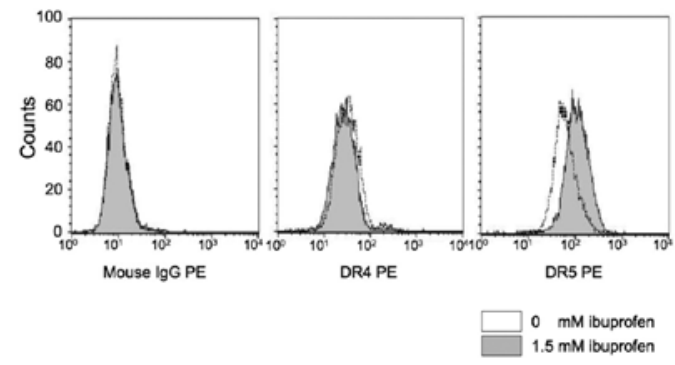

Figure 2. Ibuprofen induces DR5 expression in HCT116 cells. (A) Western blotting for TRAIL receptors, DR4 and DR5, and anti- and pro-apoptotic proteins. $\beta$-actin was used as a loading control. "Nonspecific band. HCT116 cells were treated with the indicated concentrations of ibuprofen for $24 \mathrm{~h}$. (B) Cell surface DR4 and DR5 expression in HCT116 cells treated with $1.5 \mathrm{mM}$ ibuprofen for $24 \mathrm{~h}$. Cells were stained with isotype control IgG and monoclonal antibodies generated against the extracellular domain of TRAIL receptors DR4 and DR5. Data were analyzed by flow cytometry. White histogram, DMSO; gray histogram, ibuprofen. (C) HCT116 cells were treated with the indicated concentrations of ibuprofen for $24 \mathrm{~h}$. The effects were analyzed as in (B). The Y-axis represents the geometric mean values of the cell populations in the histograms. (D) Quantitative real-time RT-PCR of DR5 mRNA in HCT116 cells treated with the indicated concentrations of ibuprofen for $24 \mathrm{~h}$. The internal control was GAPDH. Data are the means \pm SD of 3 determinations. ${ }^{* *} \mathrm{P}<0.01$ (vs. DMSO).

TRAIL-induced apoptosis, we examined the alterations in protein expression by treating HCT116 cells with ibuprofen for $24 \mathrm{~h}$. First, we carried out western blotting for TRAIL receptors, DR4 and DR5, and several anti- and pro-apoptotic proteins (Fig. 2A). Ibuprofen significantly upregulated the expression of DR5, but not DR4. Ibuprofen also decreased the expression of survivin and XIAP. In contrast, Bcl-2, c-IAP1 and Bax were not significantly changed. Next we examined the expression levels of DR4 and DR5 in the membrane fraction measured by flow cytometry (Fig. 2B and C). Ibuprofen 
A

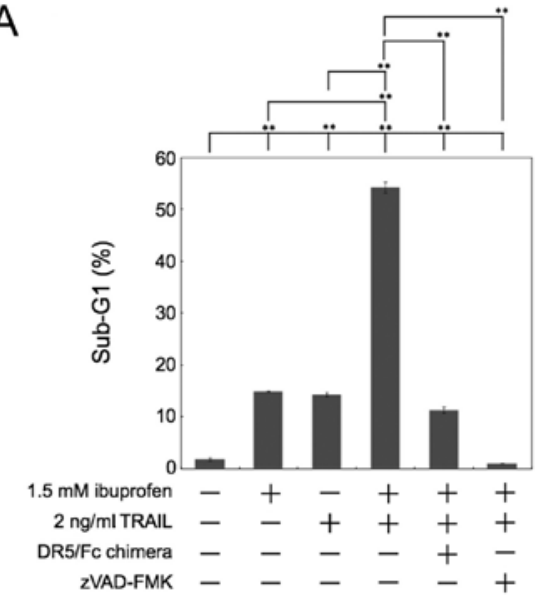

B

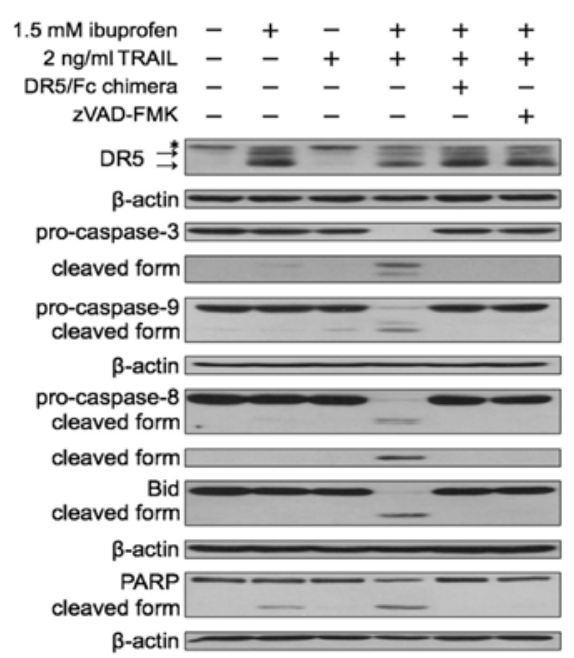

Figure 3. The combination of ibuprofen and TRAIL cleaves caspases and a substrate of caspases, PARP. (A) DR5/Fc chimera and caspase inhibitor block apoptosis enhanced by the combination of ibuprofen and TRAIL. HCT116 cells were treated with $1.5 \mathrm{mM}$ ibuprofen with or without $2 \mathrm{ng} / \mathrm{ml}$ TRAIL for $24 \mathrm{~h}$, and/or DR5/Fc chimera, and/or the zVAD-FMK pan-caspase inhibitor. Sub-G1 populations were analyzed by flow cytometry. Data are the means \pm $\mathrm{SD}$ of 3 determinations. ${ }^{* *} \mathrm{P}<0.01$. (B) Effects of the combination of ibuprofen and TRAIL on caspases, Bid and PARP in HCT116 cells. HCT116 cells were treated with $1.5 \mathrm{mM}$ ibuprofen with or without $2 \mathrm{ng} / \mathrm{ml} \mathrm{TRAIL}$, and/or DR5/Fc chimera, and/or zVAD-FMK for $24 \mathrm{~h}$. Western blot analysis was carried out with anti-caspase-3, $-8,-9$,-Bid and -PARP antibodies. $\beta$-actin was used as a loading control. "Nonspecific band.

at $1.5 \mathrm{mM}$ did not change the expression of DR4, but apparently increased DR5 expression. Furthermore, we analyzed the DR5 mRNA level after treatment with ibuprofen at the indicated concentrations for $24 \mathrm{~h}$ by quantitative real-time RT-PCR (Fig. 2D). Ibuprofen at $1.5 \mathrm{mM}$ increased DR5 mRNA expression $\sim 5$-fold.

Combination of ibuprofen and TRAIL cleaves caspases and a substrate of caspase PARP. We next investigated whether the sub-G1 population reflects caspase-dependent apoptosis by inhibitors of caspase. The apoptosis induced by the combination of ibuprofen and TRAIL was almost completely inhibited by the pan-caspase inhibitor zVADFMK (Fig. 3A). Next, we used a recombinant human DR5/ Fc chimeric protein, which has a dominant-negative function against DR5. As shown in Fig. 3A, the apoptosis induced by
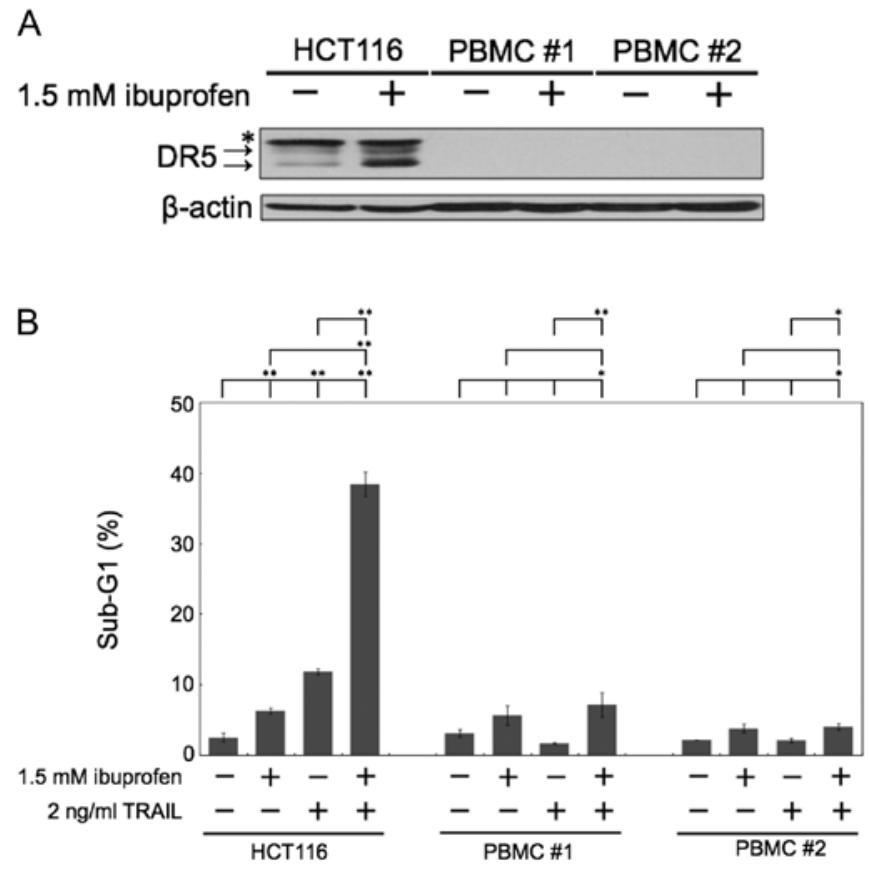

Figure 4. The combination of ibuprofen and TRAIL does not induce apoptosis in normal human peripheral blood mononuclear cells. (A) HCT116 cells and normal human human peripheral blood mononuclear cells (PBMCs) were treated with $1.5 \mathrm{mM}$ ibuprofen for $24 \mathrm{~h}$. Western blot analysis was carried out with an anti-DR5 antibody. $\beta$-actin was used as a loading control. "Nonspecific band. (B) HCT116 cells and normal human PBMCs were treated with $1.5 \mathrm{mM}$ ibuprofen and/or $2 \mathrm{ng} / \mathrm{ml}$ TRAIL for $24 \mathrm{~h}$. Sub-G1 populations were analyzed by flow cytometry. Data are the means \pm SD of 3 determinations. ${ }^{* *} \mathrm{P}<0.01$.

the combination of ibuprofen and TRAIL was effectively blocked by DR $5 / \mathrm{Fc}$ chimera. Thus, these results demonstrated that the enhancement of apoptosis caused by the combination occurred in a caspase-dependent manner and via the interaction between TRAIL and DR5. Furthermore, we performed western blot analysis of caspase- $3,-8,-9$, Bid and PARP in cells treated with ibuprofen and/or TRAIL (Fig. 3B). Bid is a substrate of caspase- 8 and is cleaved during the activation of TRAIL signaling. Combined treatment with ibuprofen and TRAIL markedly induced the cleavage of caspases, Bid and PARP. Moreover, the DR5/Fc chimeric protein and zVADFMK effectively blocked the cleavage of caspases, Bid and PARP induced by the combination treatment. These results also indicate that the combination of ibuprofen and TRAIL induces apoptosis dependent on caspases and TRAIL-DR5 interaction.

Combination of ibuprofen and TRAIL does not induce apoptosis in normal human peripheral blood mononuclear cells $(P B M C s)$. We next examined the effect of ibuprofen treatment on normal human cells. The major side effect of chemotherapeutic agents is pancytopenia, the dysfunction of hematopoietic cells during clinical treatment. Thus, we used normal human PBMCs as a comparison subject. In normal human PBMCs, the level of DR5 expression was barely expressed, and ibuprofen did not induce DR5 protein expression (Fig. 4A). Noteworthy, the combination of ibuprofen and TR AIL did not induce apoptosis in normal human PBMCs, although it markedly induced apoptosis in HCT116 cells (Fig. 4B). 


\section{Discussion}

There is epidemiological and experimental evidence that NSAIDs confer a chemopreventive effect against various types of tumors. Although NSAIDs exert anticancer effects on colorectal cancer, their precise mechanisms are still controversial.

Moreover, several studies suggest that various NSAIDs, such as aspirin, sulindac sulfide and diclofenac, sensitize cancer cells to TRAIL-induced apoptosis. Ibuprofen, an NSAID, has been widely used as a safe OTC drug, but it has not been reported whether it enhances the cytocidal effect of TRAIL. In the present study, we showed for the first time that ibuprofen with TRAIL synergistically induced apoptosis. As the mechanism inducing sensitivity to TRAIL, ibuprofen upregulated the expression of a TRAIL receptor, DR5 and also decreased the expression of survivin and XIAP (Fig. 2). In previous studies, aspirin or diclofenac increased sensitivity to TRAIL without upregulation of DR4 and DR5 $(33,34)$, whereas sulindac sulfide increased DR5 expression in human colon cancer cells, resulting in enhanced TRAIL sensitivity (35-37). Therefore, we hypothesized that the behavior of ibuprofen may be similar to that of sulindac sulfide against colon cancer cells. In order to confirm this hypothesis, further verification experiments are necessary and are in preparation.

Although NSAIDs exert anticancer effects on colorectal cancer by COX-dependent and -independent mechanisms (38), we used HCT116 cells to examine the effect of ibuprofen on stimulating TRAIL sensitivity in this study. HCT116 cells lack expression of COX-2 protein with very low expression of COX-1 (39); therefore, we considered that the effect of ibuprofen on HCT116 cells was a COX-independent mechanism.

Side effects caused by therapeutic drugs are crucial problems in antitumor therapy. NSAIDs are frequently prescribed worldwide, and their tolerance is better than other anticancer drugs. Above all, the most serious adverse effects of NSAIDs occur in the gastrointestinal tract. Thus, many trials have been conducted to compare the tolerability of aspirin, ibuprofen and other NSAIDs. Consequently, ibuprofen was shown to be remarkably well tolerated at OTC doses in a number of studies (40-42). Additionally, ibuprofen had the lowest incidence of significant adverse events as compared to aspirin and acetaminophen (43); however, in all studies describing the adverse effects of ibuprofen, the observation period was relatively short in order to conclude that ibuprofen is definitely safer than other NSAIDs. Therefore, long-term examination of ibuprofen is warranted. Nevertheless, in the present study, the combination of ibuprofen and TRAIL did not induce apoptosis in normal human PBMCs (Fig. 4); therefore, we believe that ibuprofen is a promising candidate as a safe chemopreventive agent against colorectal tumors.

Recently, endogenous TRAIL has been expected to be important for cancer prevention (31). From this point of view, we aimed to identify a TRAIL inducer for the application of TRAIL in cancer prevention. We previously reported that a type of lactobacillus markedly induced TRAIL expression in normal human PBMCs, thereby inducing the cytotoxic effects of PBMCs against human prostate cancer PC3 cells (44). We expect that the combination of ibuprofen and a TRAIL inducer such as lactobacillus may have a beneficial effect in cancer prevention.

In conclusion, the present findings suggest that ibuprofen is a safer chemopreventive agent than aspirin against colorectal tumors. We, therefore, confirm that ibuprofen is a safe NSAID and suggest that ibuprofen be used in clinical chemopreventive studies against colorectal adenoma or cancer.

\section{Acknowledgements}

This research was partly supported by the Japanese Ministry of Education, Culture, Sports, Science and Technology.

\section{References}

1. Weitz J, Koch M, Debus J, Höhler T, Galle PR and Büchler MW: Colorectal cancer. Lancet 365: 153-165, 2005.

2. Brasky TM, Bonner MR, Moysich KB, et al: Non-steroidal antiinflammatory drugs (NSAIDs) and breast cancer risk: differences by molecular subtype. Cancer Causes Control 22: 965-975, 2011.

3. Walter RB, Milano F, Brasky TM and White E: Long-term use of acetaminophen, aspirin, and other nonsteroidal anti-inflammatory drugs and risk of hematologic malignancies: results from the prospective Vitamins and Lifestyle (VITAL) study. J Clin Oncol 29: 2424-2431, 2011.

4. Thun MJ, Namboodiri MM and Heath CW Jr: Aspirin use and reduced risk of fatal colon cancer. N Engl J Med 325: 1593-1596, 1991.

5. Baron JA, Cole BF, Sandler RS, et al: A randomized trial of aspirin to prevent colorectal adenomas. N Engl J Med 348: 891-899, 2003.

6. Rothwell PM, Wilson M, Elwin CE, et al: Long-term effect of aspirin on colorectal cancer incidence and mortality: 20-year follow-up of five randomised trials. Lancet 376: 1741-1750, 2010.

7. Rothwell PM, Wilson M, Price JF, et al: Effect of daily aspirin on risk of cancer metastasis: a study of incident cancers during randomised controlled trials. Lancet 379: 1591-1601, 2012.

8. Ishikawa H, Nakamura T, Kawano A, Gondo N and Sakai T: Chemoprevention of colorectal cancer in Japan: a brief introduction to current clinical trials. J Gastroenterol 44: 77-81, 2009.

9. Ishikawa H, Wakabayashi K, Suzuki S, et al: Preventive effects of low-dose aspirin on colorectal adenoma growth in patients with familial adenomatous polyposis: double-blind, randomized clinical trial. Cancer Med 2: 50-56, 2013.

10. Antithrombotic Trialists' Collaboration: Collaborative metaanalysis of randomised trials of antiplatelet therapy for prevention of death, myocardial infarction, and stroke in high risk patients. BMJ 324: 71-86, 2002.

11. Adams SS, McCullough KF and Nicholson JS: The pharmacological properties of ibuprofen, an anti-inflammatory, analgesic and antipyretic agent. Arch Int Pharmacodyn Ther 178: 115-129, 1969.

12. Chan AT, Ogino S and Fuchs CS: Aspirin and the risk of colorectal cancer in relation to the expression of COX-2. N Engl J Med 356: 2131-2142, 2007.

13. Ogino S, Kirkner GJ, Nosho K, et al: Cyclooxygenase-2 expression is an independent predictor of poor prognosis in colon cancer. Clin Cancer Res 14: 8221-8227, 2008.

14. Kawamori T, Rao CV, Seibert K and Reddy BS: Chemopreventive activity of celecoxib, a specific cyclooxygenase-2 inhibitor, against colon carcinogenesis. Cancer Res 58: 409-412, 1998.

15. Solomon SD, McMurray JJ, Pfeffer MA, et al: Cardiovascular risk associated with celecoxib in a clinical trial for colorectal adenoma prevention. N Engl J Med 352: 1071-1080, 2005.

16. Baron JA, Sandler RS, Bresalier RS, et al: A randomized trial of rofecoxib for the chemoprevention of colorectal adenomas. Gastroenterology 131: 1674-1682, 2006.

17. Harris RE, Beebe-Donk J and Alshafie GA: Similar reductions in the risk of human colon cancer by selective and nonselective cyclooxygenase-2 (COX-2) inhibitors. BMC Cancer 14: 237, 2008.

18. Schönthal AH, Chen TC, Hofman FM, et al: Celecoxib analogs that lack COX-2 inhibitory function: preclinical development of novel anticancer drugs. Expert Opin Investig Drugs 17: 197-208, 2008. 
19. Bonelli P, Tuccillo FM, Calemma R, et al: Changes in the gene expression profile of gastric cancer cells in response to ibuprofen: a gene pathway analysis. Pharmacogenomics J 11: 412-428, 2011.

20. Greenspan EJ, Madigan JP, Boardman LA and Rosenberg DW: Ibuprofen inhibits activation of nuclear $\beta$-catenin in human colon adenomas and induces the phosphorylation of GSK-3 $\beta$. Cancer Prev Res 4: 161-171, 2011.

21. Harris RE, Beebe-Donk J, Doss H and Burr Doss D: Aspirin, ibuprofen, and other non-steroidal anti-inflammatory drugs in cancer prevention: A critical review of non-selective COX-2 blockade (Review). Oncol Rep 13: 559-583, 2005.

22. Taniguchi H, Horinaka M, Yoshida T, et al: Targeting the glyoxalase pathway enhances TRAIL efficacy in cancer cells by downregulating the expression of antiapoptotic molecules. Mol Cancer Ther 11: 2294-2300, 2012.

23. Taniguchi H, Yoshida T, Horinaka M, et al: Baicalein overcomes tumor necrosis factor-related apoptosis-inducing ligand resistance via two different cell-specific pathways in cancer cells but not in normal cells. Cancer Res 68: 8918-8927, 2008.

24. Yoshida T, Maoka T, Das SK, et al: Halocynthiaxanthin and peridinin sensitize colon cancer cell lines to tumor necrosis factor-related apoptosis-inducing ligand. Mol Cancer Res 5: 615-625, 2007

25. Horinaka M, Yoshida T, Shiraishi T, et al: The dietary flavonoid apigenin sensitizes malignant tumor cells to tumor necrosis factor-related apoptosis-inducing ligand. Mol Cancer Ther 5: 945-951, 2006

26. Walczak H, Miller RE, Ariail K, et al: Tumoricidal activity of tumor necrosis factor-related apoptosis-inducing ligand in vivo. Nat Med 5: 157-163, 1993.

27. Ashkenazi A, Pai RC, Fong S, et al: Safety and antitumor activity of recombinant soluble Apo2 ligand. J Clin Invest 104: 155-162, 1999.

28. Fesik SW: Promoting apoptosis as a strategy for cancer drug discovery. Nat Rev Cancer 5: 876-885, 2005.

29. Soria JC, Smit E, Khayat D, et al: Phase 1b study of dulanermin (recombinant human Apo2L/TRAIL) in combination with paclitaxel, carboplatin, and bevacizumab in patients with advanced non-squamous non-small-cell lung cancer. J Clin Oncol 28: 1527-1533, 2010.

30. Leong S, Cohen RB, Gustafson DL, et al: Mapatumumab, an antibody targeting TRAIL-R1, in combination with paclitaxel and carboplatin in patients with advanced solid malignancies: results of a phase I and pharmacokinetic study. J Clin Oncol 27: 4413-4421, 2009.

31. Zerafa N, Westwood JA, Cretney E, et al: Cutting edge: TRAIL deficiency accelerates hematological malignancies. J Immuno 175: 5586-5590, 2005.

32. Nakata S, Yoshida T, Horinaka M, Shiraishi T, Wakada M and Sakai T: Histone deacetylase inhibitors upregulate death receptor 5/TRAIL-R2 and sensitize apoptosis induced by TRAIL/APO2-L in human malignant tumor cells. Oncogene 23 6261-6271, 2004
33. Kim KM, Song JJ, An JY, Kwon YT and Lee YJ: Pretreatment of acetylsalicylic acid promotes tumor necrosis factor-related apoptosis-inducing ligand-induced apoptosis by down-regulating BCL-2 gene expression. J Biol Chem 49: 41047-41056, 2005.

34. Braun FK, Al-Yacoub N, Plötz M, Möbs M, Sterry W and Eberle J: Nonsteroidal anti-inflammatory drugs induce apoptosis in cutaneous T-cell lymphoma cells and enhance their sensitivity for TNF-related apoptosis-inducing ligand. J Invest Dermatol 132: 429-439, 2012.

35. Huang Y, He Q, Hillman MJ, Rong R and Sheikh MS: Sulindac sulfide-induced apoptosis involves death receptor 5 and the caspase 8-dependent pathway in human colon and prostate cancer cells. Cancer Res 61: 6918-6924, 2001.

36. Sinicrope FA and Penington RC: Sulindac sulfide-induced apoptosis is enhanced by a small-molecule Bcl-2 inhibitor and by TRAIL in human colon cancer cells overexpressing Bcl-2. Mol Cancer Ther 4: 1475-1483, 2005.

37. Heijink DM, Jalving M, Oosterhuis D, et al: TNF-related apoptosis-inducing ligand cooperates with NSAIDs via activated Wnt signalling in (pre)malignant colon cells. J Pathol 223: 378-389, 2011.

38. Ricchi P,Zarrilli R, Di Palma A and Acquaviva AM: Nonsteroidal anti-inflammatory drugs in colorectal cancer: from prevention to therapy. Br J Cancer 88: 803-807, 2003.

39. Sheng H, Shao J, Kirkland SC, et al: Inhibition of human colon cancer cell growth by selective inhibition of cyclooxygenase- 2 . J Clin Invest 99: 2254-2259, 1997.

40. Bjarnason I: Gastrointestinal safety of NSAIDs and over-thecounter analgesics. Int J Clin Pract (Suppl) 178: 37-42, 2013.

41. Schnitzer TJ, Burmester GR, Mysler E, et al: Comparison of lumiracoxib with naproxen and ibuprofen in the Therapeutic Arthritis Research and Gastrointestinal Event Trial (TARGET), reduction in ulcer complications: randomised controlled trial. Lancet 364: 665-674, 2004.

42. Lugardon S, Lapeyre-Mestre M and Montastruc JL: Upper gastrointestinal adverse drug reactions and cyclo-oxygenase-2 inhibitors (celecoxib and rofecoxib): a case/non-case study from the French Pharmacovigilance Database. Eur J Clin Pharmacol 60: 673-677, 2004.

43. Van GE, Jones JK, Moore N, Parc JM, Wall R and Schneid H: A large simple clinical trial prototype for assessment of OTC drug effects using patient-reported data. Pharmacoepidemiol Drug Saf 14: 249-255, 2005

44. Horinaka M, Yoshida T, Kishi A, et al: Lactobacillus strains induce TRAIL production and facilitate natural killer activity against cancer cells. FEBS Lett 584: 577-582, 2010. 